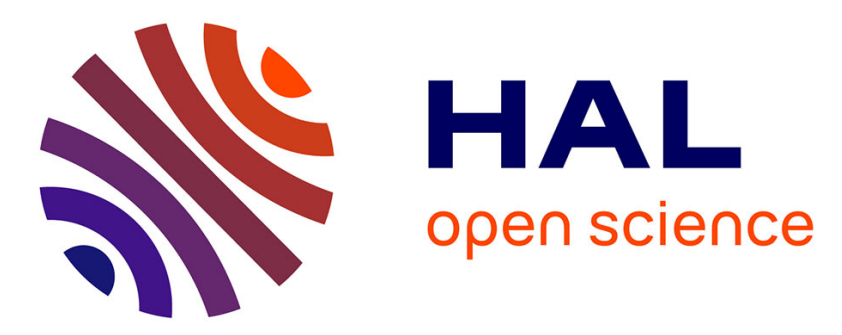

\title{
Numerical prediction of long-term settlements over tunnels in clay
}

Dong-Mei Zhang, Hong-Wei Huang, Pierre-Yves Hicher

\section{To cite this version:}

Dong-Mei Zhang, Hong-Wei Huang, Pierre-Yves Hicher. Numerical prediction of long-term settlements over tunnels in clay. Tunnelling and Underground Space Technology, 2004, 19 (4 5), pp.379-386. 10.1016/j.tust.2004.02.009 . hal-01007126

\section{HAL Id: hal-01007126 https://hal.science/hal-01007126}

Submitted on 18 Apr 2017

HAL is a multi-disciplinary open access archive for the deposit and dissemination of scientific research documents, whether they are published or not. The documents may come from teaching and research institutions in France or abroad, or from public or private research centers.
L'archive ouverte pluridisciplinaire $\mathbf{H A L}$, est destinée au dépôt et à la diffusion de documents scientifiques de niveau recherche, publiés ou non, émanant des établissements d'enseignement et de recherche français ou étrangers, des laboratoires publics ou privés. 


\title{
Numerical Prediction of Long-term Settlements over Tunnels in Clay
}

\author{
D.M. Zhang ${ }^{1,2}$, H.W. Huang ${ }^{1}$, P.Y. Hicher ${ }^{2}$ \\ ${ }^{1}$ Department of Geotechnical Engineering, Tongji University, Shanghai, China \\ ${ }^{2}$ Laboratory of Civil Engineering, Ecole Centrale de Nantes, Nantes, France
}

\begin{abstract}
The long-term settlements over tunnels can be rather significant, particularly when tunnels are embedded in soft and compressible soils. The long-term settlement can be predicted based on the stress-strain-time relationship of soft clay using multiple-step FEM. The influence of drainage condition of tunnel linings on the evolution of long-term surface settlement, as well as ground loss, are simulated with the multiple-step numerical procedure, and some conclusions are drawn from the numerical simulations. Finally, a case study is also performed and a satisfaction agreement between the predicted long-term settlement and the observed one is obtained.
\end{abstract}

\section{INTRODUCTION}

The long-term settlement can be significant, particularly when tunnels are embedded in soft and compressible soils. It is concluded by Shirlaw, based on comprehensive field data, that typically the increase in settlements over long-term is of the order of 30\%-90\% of the total settlement, and that in many cases a widened settlement trough develops (Shirlaw, 1995). This is confirmed, for example, by the observed settlements over a period of 11 years reported by O'Reilly et al.(1991) for a 3m diameter tunnel constructed in normally consolidated silty clay in Grimsby, England (shown as Figure 1a). The final equilibrium of settlement was achieved after about 10 years, and the corresponding transverse surface profiles show a significant widening with time. Similar widening has been reported by a number of authors (Glossop, 1982; Shirlaw, 1995). The increase of long-term settlement reached 60$90 \%$ of the total settlement for No.2 metro tunnel in Shanghai, meanwhile the width of the settlement rose from 2.645a in the first month to 2.742a (a is the radius of tunnel) in the third month after construction (Lee et al. 1998, shown in Figure 1b). The long-term settlement can affect the function of the tunnel and the safety of the surroundings.

It is widely accepted that the effects of time on strength and deformation characteristics of soils, especially of saturated cohesive soft soils, plays an important role in a variety of geotechnical engineering activities where either rapid or long-term response is concerned (Liang et al., 1992). Accordingly, it is necessary to build a constitutive law that can be used to predict the time-dependent deformation around the tunnel. Consequently, an elastic-viscoplastic constitutive model coupled with Biot's consolidation theory was developed and used in the long-term settlement prediction over urban tunnels. 

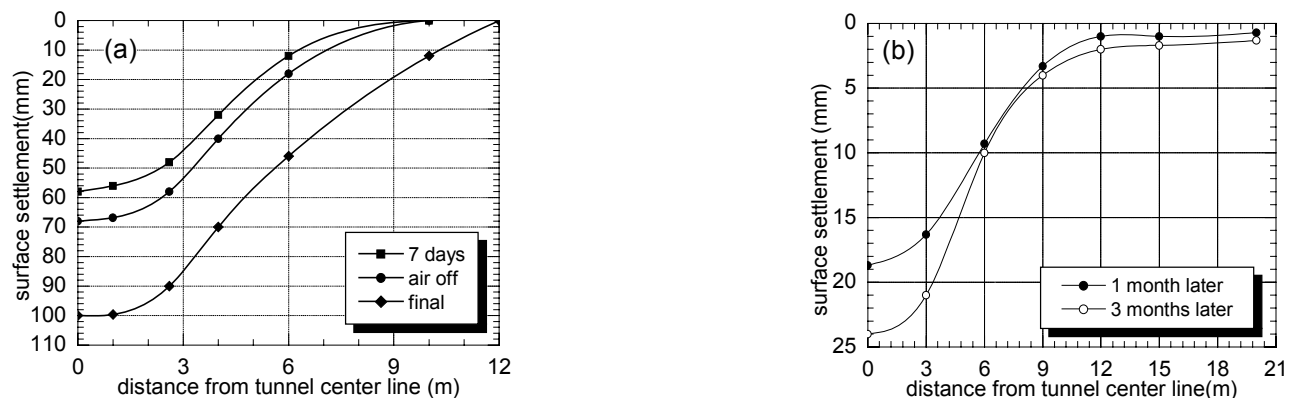

Fig.1 Long-term transverse surface settlement troughs over (a) Grimsby Tunnel in silty clay in England (after O'Reilly et al., 1991), and (b) Shanghai No.2 Tunnel in soft clay (after Lee et al., 1998)

\section{ELASTIC VISCO-PLASTIC CONSTITUTIVE MODEL}

\subsection{Visco-plastic flow rule}

The visco-plastic constitutive model was established using the results of both triaxial and oedometer tests (the experimental results are given in Zhang et al., 2003). The construction of the viscoplastic model was undertaken based on the framework of the Modified Cam-clay model (Roscoe et al., 1968). The viscoplastic strain rate follows the framework proposed by Perzyna with associated flow rule (Perzyna, 1963,1969).

The constitutive model is then implemented into the FEM code CESAR_LCPC coupled with Biot's consolidation theory. Consequently, the long-term response of urban tunnel can be numerically estimated. The numerical simulation on long-term settlement over urban tunnels is performed with the background of Shanghai metro line 2. The tunnel lining for Shanghai metro line 2 is $6.2 \mathrm{~m}$ in external diameter and $5.5 \mathrm{~m}$ in internal diameter. The average depth to the center-line of the tunnel is about $11 \mathrm{~m}$, which is about 1.8D (D is the tunnel diameter). The tunnel was excavated by EPB shield machine. The shield body is $6.24 \mathrm{~m}$ long with $6.34 \mathrm{~m}$ in diameter. Correspondingly, the clearance between the external diameters of shield body and the tunnel, which is usually named physical gap $G_{p}$ according to the definition of Lee et al. (1992), will reach $140 \mathrm{~mm}$. The effective back grouting pressure is determined as $0.25 \mathrm{MPa}$ according to the in-situ measurements.

\section{NUMERICAL SIMULATION PROCEDURE}

The numerical simulation was performed with 8-node isoparametric finite elements under the assumption of plane strain conditions. Correspondingly, the FEM mesh of the tunnel is shown in Fig.2.

\subsection{Boundary conditions}

The boundary conditions in the numerical simulation on long-term settlements contain the following two types, one is the displacement boundary condition, and the other is the drainage condition.

A free displacement boundary condition was adopted at the ground surface. It is assumed that no horizontal nor vertical displacement takes place at the lower boundary, for it is beyond the influence of tunnel construction. The lateral displacements at left- and right- hand boundary are both fixed as zero. The left-hand boundary is the line of symmetry. 
The drainage condition is not a constant, but a variable during the different development stages of short-term and long-term settlements. The drainage condition at the ground surface is assumed to be free, hence the excess pore pressure will be kept as zero along the ground surface; meanwhile the lower boundary as well as the left-hand boundary condition are considered to be impermeable, in order to prevent the pore pressure dissipation across the boundary during the settlement development. However, the right-hand boundary is taken as impermeable, because of the low permeability of the soil around the tunnel during the development of short-term settlement, while the pore-pressure is assuned to maintain the hydrostatic pore-pressure at the right-hand boundary during the long-term settlement evolution. That means the right-hand boundary is taken as impermeable during short-term settlement and if the right-hand boundary is taken as a constant head boundary it is permeable in one direction only during the long-term settlement. The tunnel lining is also assumed to be an impermeable boundary during the short-term settlement, but permeable during the long-term settlement; however, this is questionable and was studied in the long-term settlement simulation.

The initial effective stresses and hydrostatic pore pressure were calculated based on the weight of the soil and the underground water condition.

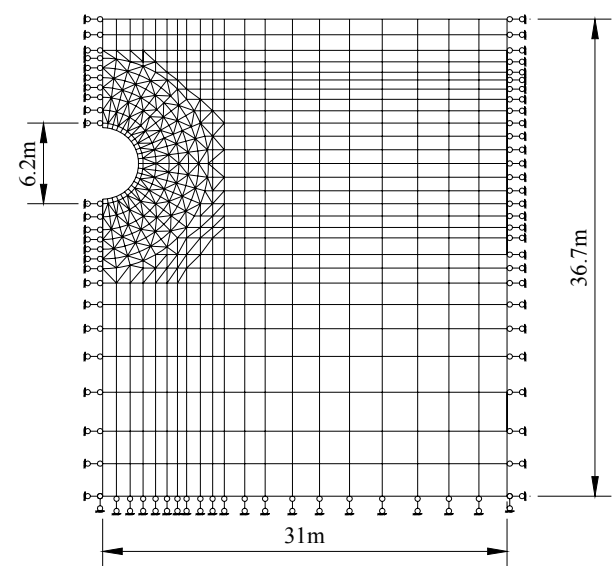

Fig.2 FEM mesh in numerical simulation

\subsection{Numerical simulation procedure}

The evolution of long-term (or post-construction) settlement was simulated using 4 consecutive steps. The 4 consecutive steps correspond to different stages of the development of surface settlement over tunnels, and their correlations are as follows: STEP 0 means the initial state of the ground before taking account of the influence of tunnelling, STEP 1 represents the heave (or settlement) of the ground before the shield machine reaches, STEP 2 represents the shield machine just passes the studied position, STEP 3 is the final case in the simulation, where the long-term settlement occurs. The numerical results for each step are the initial state of the next step since the 4 steps are consecutive both in time and stress state. Among the 4 steps, STEP 0,1 and 3 are simulated using the stress boundary conditions, while the displacement boundary condition is adopted in STEP 2 to simulate the closure of the tail void during the tunnel advances.

\subsection{Determination of parameters}

The parameters involved in the numerical simulation can be divided into two types. One type is the mechanical parameters of soils and tunnel segments. The other type is related to the tunnel construction process. The mechanical parameters of soils can be obtained through laboratory triaxial and oedometer tests, and are listed in table 1. Considering the influence of shield tunneling on the surrounding soil, the strength of the soils is discounted to some extent, based on the in-situ 
measurement, in step 2. The tunnel construction parameters include the advance rate of shield machine, the physical gap and the grouting pressure are presented in table 2 .

Table 1 Mechanical parameters of soils of Shanghai

\begin{tabular}{lcccccc}
\hline Depth $(\mathrm{m})$ & $0 \sim 2.40$ & $2.40 \sim 4.0$ & $4.0 \sim 8.0$ & $8.0 \sim 17.7$ & $17.7 \sim 28.7$ & $28.7 \sim 31.7$ \\
\hline Young's modulus $E(\mathrm{kPa})$ & 2395 & 2032 & 1293 & 2710 & 3318 & 4216 \\
Poisson's ratio $v$ & 0.35 & 0.35 & 0.35 & 0.35 & 0.35 & 0.35 \\
Water content $W(\%)$ & 34.8 & 40.5 & 51.1 & 34.8 & 33.0 & 23.8 \\
Compression index $\lambda$ & 0.121 & 0.10 & 0.230 & 0.065 & 0.065 & 0.065 \\
Recompression index $k$ & 0.015 & 0.010 & 0.031 & 0.008 & 0.008 & 0.008 \\
Slope of C.S.L. $M$ & 1.32 & 1.14 & 1.01 & 1.20 & 1.47 & 1.20 \\
Permeability $k\left(10^{-9} \mathrm{~m} / \mathrm{s}\right)$ & 3.27 & 2.66 & 1.82 & 3.00 & 247 & 3.00 \\
Void ratio $e$ & 0.97 & 1.13 & 1.44 & 1.01 & 0.98 & 0.70 \\
\hline
\end{tabular}

Table 2 Tunnel construction parameters

\begin{tabular}{ccc}
\hline Advance rate of shield machine & Physical gap & Grouting pressure \\
\hline $\mathrm{m} / \mathrm{d}$ & $\mathrm{mm}$ & $\mathrm{MPa}$ \\
\hline 12 & 140 & 0.25
\end{tabular}

\section{DEVELOPMENT OF LONG-TERM SETTLEMENTS}

The development of long-term settlement is dependent on many factors such as drainage condition of the tunnel linings, back-grouting, over-excavation, surcharge over the tunnel, time-dependent properties of soils around the tunnel and so on. Here, only the influence of drainage condition on the evolution of long-term settlements over tunnels are considered.

\subsection{Influence of permeability of the tunnel on the evolution of long-term settlements}

O'Reilly et al.(1991) and Shin et al. (2001) concluded that the drainage condition of the tunnel had a significant influence on both the magnitude and distribution of long-term settlement. The permeability of the tunnel is described by the relative value to the permeability of surrounded soil in the multiplestep numerical simulation. Accordingly, the influence of permeability of tunnels is studied for the following four different cases: (1) impermeable, $k_{t} / k_{v}=\infty$, where $k_{t}, k_{v}$ represent the permeability of tunnel and the surrounding soil respectively. (2) finite permeability: $k_{t} / k_{v}=0.01$. (3) finite permeability: $k_{t} / k_{v}=0.1$. (4) fully permeable: $k_{t} / k_{v}=1$. The evolutions of long-term surface settlements over tunnels with the four different permeability cases are presented in Fig.3.
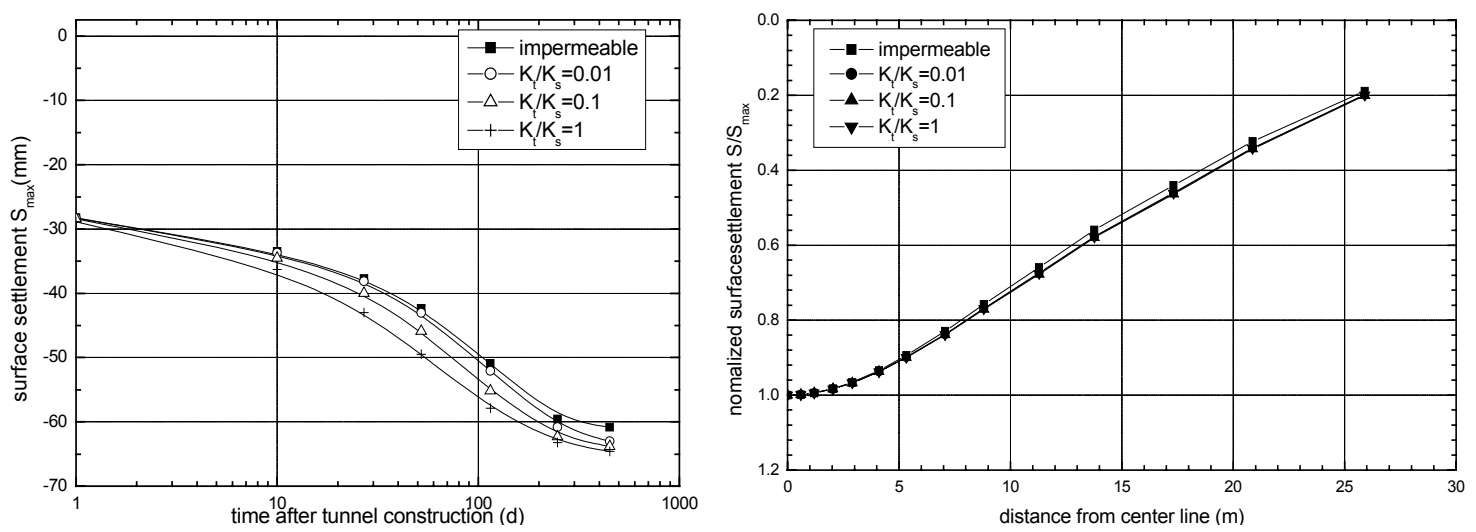
Fig. 3 Long-term surface settlements for different lining permeability with time
Fig. 4 Long-term transverse surface settlement troughs for different lining permeabilities

Fig. 3 reveals that the magnitude of maximum surface settlement is smaller at any time and reaches stability more quickly with an impermeable lining. The higher the permeability of tunnel lining, the more the surface settlement.

The long-term transverse surface settlement troughs, normalized to the corresponding maximum surface settlements, are shown in Fig. 4.

The normalized long-term transverse surface settlement troughs shown in Fig.4 are independent of the permeability and exhibit uniform shape. Additionally, they can be described by Peck's empirical formu -lation (equation 1) (Peck, 1969).

$$
S(x)=S_{\text {max }} \exp \left(-\frac{x^{2}}{2 i^{2}}\right)
$$

However, the evolution of the width of the surface settlement troughs ( $i$ ), estimated using equation 2, is closely associated with the permeability of tunnels linings, as shown in Fig.5.

$$
S(i)=0.606 S_{\max }
$$

It can be clearly found from Fig. 5 that $i$ continuously increases with both time and the permeability of tunnel linings until it reaches the stability during the evolution of long-term settlements under drainage condition. However, $i$ increases with time within a certain period, for example 300 days in Fig.5, and thereafter it begins to decrease when time exceed this period prove the tunnel linings are impermeable.

The corresponding predicted ground loss with different permeability of tunnel linings is presented in Fig.6 via time.

The evolution of ground loss with time corresponding to different permeability is similar with that of the width of long-term transverse surface settlement troughs $i$.

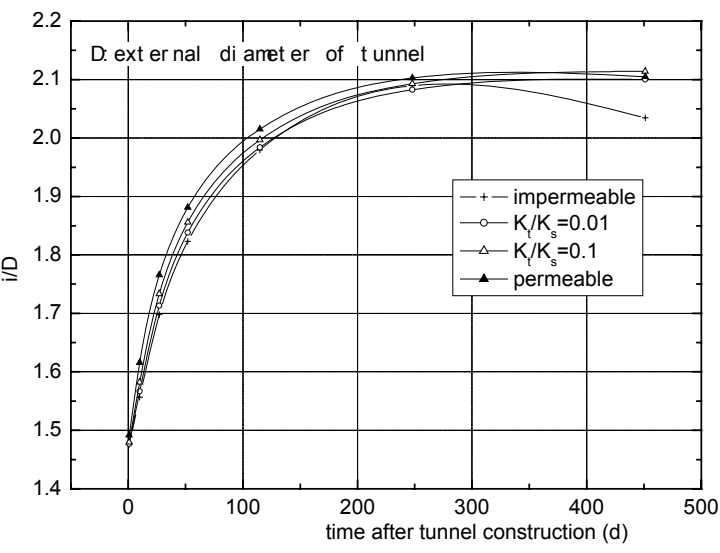

Fig.5 Width of long-term transverse surface settlement troughs with time with different permeability

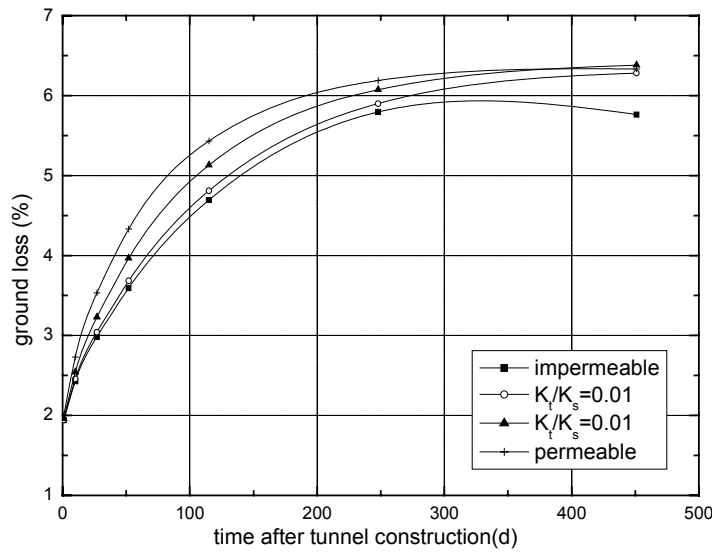

Fig. 6 Ground loss with time with varied permeability of tunnel 


\section{A BACK-ANALYSIS}

A back-analysis was performed on the Shanghai metro No.2. The FEM meshes, the boundary and drainage conditions, and numerical procedures were as presented above. The calculated surface settlements and the observed ones are shown in Fig.7.

In Fig.7, the creep parameters used for the various analysis are: $\mu_{1}=1 \times 10^{-8}, n_{1}=1 \times 10^{-3}$, $\mu_{2}=5 \times 10^{-9}, n_{2}=5 \times 10^{-4}$, and $\mu_{1 f}=5 \times 10^{-9}, n_{1 f}=5 \times 10^{-4}, \mu_{2 f}=1 \times 10^{-9}, n_{2 f}=1 \times 10^{-4}$.

Fig.7 demonstrates that: (1) the tunnel acts as a drain in the long-term. An encouraging agreement is found between the calculated and observed long-term surface settlement with $k_{t} / k_{v}=0.001$. (2) The time-dependent properties of the soils around the tunnel enlarge the long-term settlements.

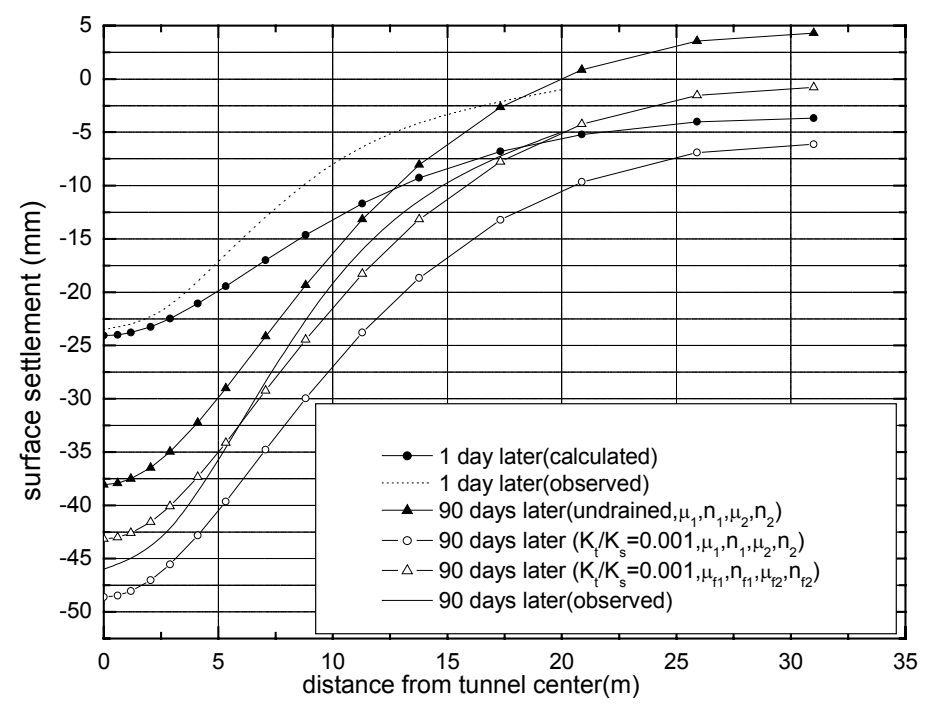

Fig.7 Comparison of calculated and in-situ measured surface settlements

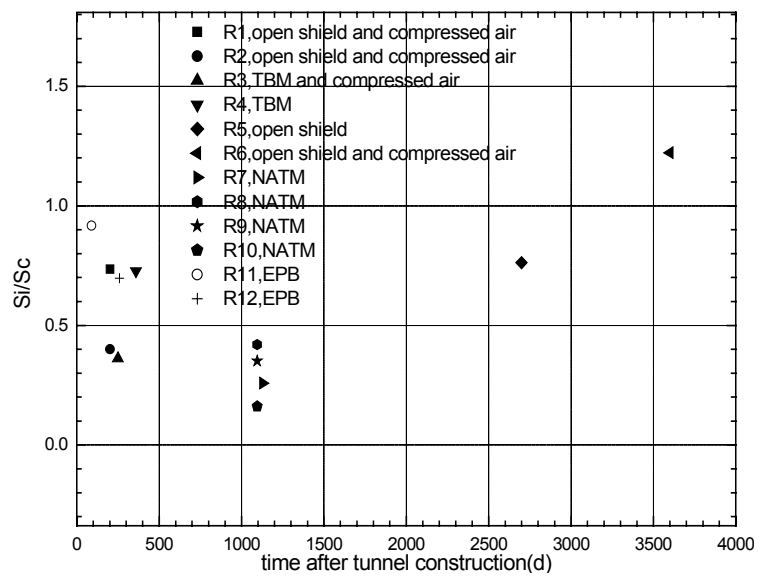

Fig. 8 The ratio of max. immediate settlement to max. long-term settlement

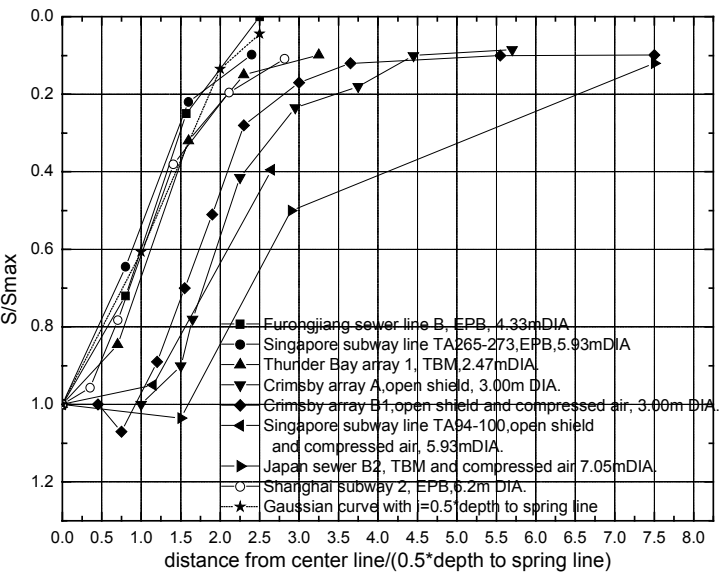

Fig. 9 Long-term surface settlement troughs corresponding to different tunnel excavation methods 
The calculated and observed long-term settlements of Shanghai metro as well as those found in the literature are presented in Fig. 8 for a full understanding of the evolution of the long-term settlement of Shanghai metro.

Fig. 8 shows that the long-term settlements of Shanghai metro were significant, and couldn't be neglected. The transverse long-term surface settlement troughs corresponding to different tunnel excavation methods are presented in Fig. 9, to illustrate the development of surface settlement troughs in the long-term behavior of tunnels in clays.

Fig.9 shows that the surface settlement troughs do not change much during the long-term if the EPB tunnelling is adopted, and can be well described by Peck's empirical formula (equation 2). However, the shape of long-term surface settlement troughs varies significantly between TBM and open shield methods. Hence, the evolution of long-term surface settlement troughs seems to be dependent on the tunnel excavation method, and it is consistent with the findings of Mair and Taylor (1997) and Shirlaw (1993).

\section{CONCLUSIONS}

Coupling the time-dependent stress-strain behavior of soils with a multiple-step numerical simulation method, the evolution of long-term settlement of tunnels in clays was studied and the following conclusions were obtained:

1. The Shanghai No.2 metro acts as a drain in the long-term. When the tunnel ling is permeable, surface settlement, ground loss and width of surface settlement troughs increase with time during the equilibrium period. In contrast, ground loss begins to decrease, after an initial increase, with time, under undrained condition.

2. The long-term settlement of Shanghai No.2 was significant.

3. The evolution of long-term surface settlement troughs is dependent on the tunnel excavation methods. The shapes of surface settlement troughs do not change much in the long-term using the EPB tunnel excavation method.

\section{REFERENCES}

Glossop, N.H., O’ Reilly, M. P., 1982. Settlement caused by tunnelling through soft marine clay. Tunnels and Tunnelling (9) October, pp.13-16.

Lee, K. M., Ji, H. W., Shen, C. K., Liu, J. H., Bai, T. H., 1998. Ground Response to the Construction of Shanghai Metro Tunnel-Line 2. Soils and Foundations 39(3), pp.113-134.

Lee, K.M., Rowe, R.K., Lo, K.Y., 1992. Subsidence due to tunnelling: Estimating the gap parameter. Canadian Geotechnical Journal, 29(6), pp. 929-940.

Liang, R.Y., Ma, F., 1992. A unified elasto- viscoplasticity model for clays, part I: theory.

Computers and Geotechnics 13 (2), pp.71-87.

Mair, R. J., Taylor, R. N., 1997. Theme lecture: Bored tunneling in the urban environment. Proceedings of the Fourteenth International Conference on Soil Mechanics and

Foundation Engineering, pp. 2353-2385.

O'Reilly, M. P., Mair, R. J., Alderman, G. H., 1991. Long-term settlements over tunnels: an elevenyear study at Grimsby. Proceedings of Conference Tunnelling, London, Institution of Mining and Metallurgy, pp. 55-64.

Peck, R. B., 1969. Deep excavation and tunneling in soft ground. Proceeding 7th International Conference on Soil Mechanics and Foundation Engineering. 3, pp.1469-1472. 
Perzyna, P., 1963. The constitutive equation for rate sensitive plastic materials. Quarterly of Applied Mathematics 20, pp.321-332.

Perzyna, P., 1969. Fundamental problems in viscoplasticity. Advances in Applied Mechnics 9, pp. 243-277.

Roscoe, K.H., Burland, J.B., 1968. On the generalized stress-strain behaviour of wet clay. In Engineering Plasticity. Edited by Editor J.Heyman and F.A. Leckie. Cambridge University Press, Cambridge, U.K., pp.535-609.

Shin, J. H., Addenbrooke, T. L., Potts, D. M., 2001. A numerical study of the effect of groundwater movement on long-term tunnel behavior. Géotechnique 52(6), pp. 391-403.

Shirlaw, J. N., 1995. Observed and calculated pore pressures and deformations induced by an earth balance shield: Discussion1. Canadian Geotechnical Journal 32, pp.181-189.

Shirlaw, J. N.,1993. Pore pressure around tunnels in clay: 1Discussion. Canadian Geotechnical Journal 30, pp. 1044-1046.

Yin J.H., Graham J., 1999. Elastic viscoplastic modelling of the time-dependent stress-strain behaviour of soils. Canadian Geotechnical Journal, 36(4), pp.736-745

Zhang D.M., Hicher P.Y., Huang, H.W., 2003. Time-dependent stress-strain behaviour of natural soft clay. 3rd International symposium on Deformation Characteristics of Geomaterials. Lyon, France. (in press). 